\title{
THE EVALUATION OF THE PRACTICAL ADHESION STRENGTH OF BIOCOMPATIBLE THIN FILMS BY FUZZY LOGIC EXPERT SYSTEM AND INTERNATIONAL STANDARDS
}

\author{
Vladimír Socha - Patrik Kutílek — Slávka Vitečková *
}

\begin{abstract}
This work focuses on describing an evaluation method used in nano- and micro-thin films based on fuzzy logic expert systems. The aim is the elimination of comparison complications with mechanical properties of tin films, practical adhesion being one of the most important characteristic of tin films. The basic method for evaluating the practical adhesion strength is scratch test method, while the issue is that research teams use measurement methods based on the non-uniform measurement conditions of adhesion of biocompatible thin films. The authors tested new evaluation method and procedure based on international standards and fuzzy rule based expert system in order to eliminate the problem of comparison of practical adhesion of the films. The article concentrates on testing and using the fuzzy logic expert system designed based on international standards for evaluating adhesion of thin films in nano and micro dimensions. The materials used for tests of the fuzzy expert system were DLC biocompatible layers and substrate a titanium alloy Ti6Al4V
\end{abstract}

K e yw ords: international standards, fuzzy expert system, practical adhesion, scratch test, thin film

\section{INTRODUCTION}

In recent industry, nano- and micro-thin layers are a popular choice in many of its branches, for its practical adhesion as one of the most important mechanical properties, which is a key parameter for every coating [13]. Scratch test was chosen from among a wide choice of adhesion strength measurement methods. However, the practical adhesion strength, ie the work done to separate the thin film from the substrate, is very sensitive to the measurement and evaluation conditions, such as the strain rate, roughness, thickness, etc. Recently, the situation in scientific and research institutions is that they do not use uniform measurement and evaluation conditions, and suitable comparison procedure in the research on nano- and micro-biocompatible films, despite that the measurement of practical adhesion is highly influenced by the conditions of measurement, nevertheless international industrial standards are already used and recognized in evaluating adhesion of macro- and micro-thin films. So far, there are international standards for Europe, USA and other nations describing scratch tests[1-4], and for the purposes of this paper, ISO 1071-3, ISO 20502, ISO 1518, ASTM C1624-05, ASTM D7187-05 will be observed, which apply mostly for macro-scratch testers, however are utilized also for measuring nano- and microlayers [5].

The surfaces of samples in scratch tests undergo pulling a (mostly diamond) stylus against them under a normal force [1-4]. The recommended shape of stylus is spherical Rockwell C, $200 \mu \mathrm{m}$ radius or alternatively a smaller one [6]. The crucial characteristics of Rock- well $\mathrm{C}$ are a conical diamond intender with an included angle of $120^{\circ}$, and spherical tip of $200 \mu \mathrm{m}$ [3]. Three test operations are usually agreed to be sufficient for coatings of the thickness ranging from 0.1 to $20 \mu \mathrm{m}$ [6]. To avoid undesired and excessive stylus wear, the pre-defined maximum load $\left(\mathrm{L}_{\max }\right)$ should be selected to produce the desired maximum level of coating damage [3].

Progressive loading scratch test mode (PLST), constant load scratch test mode and multi-pass scratch test mode were modes of measurement used in the scratch tests. Progressive load scratch test, which is defined for all the mentioned standards, is however recommended by many authors [9-11]. In this case, the method consist in the load on the indenter increasing linearly as the indenter moves across the test surface at a constant speed until the failure, which sets the value of the critical normal load. This method is considered efficient in the testing of coated surfaces $[7,12-16]$, however the application to coatingto-substrate adhesion assessment has been questioned $[6,16,17]$. The respective kind of the failure depends on the properties of substrate and coating. Holmberg [18] divides the material response to loading conditions into threes phases implemented to standards [1-4]. The formation of cracks in the groove of a scratch tester has been described in $[7,16,18,19]$, namely angular cracks, parallel cracks, transverse semi-circular cracks, coating chipping, coating spalling and coating breakthrough [6].

Even though the standards can be utilized in measuring nano- and micro-films in medical applications $[5,6]$, they are not used in testing of new thin layers. The overall comparison in research findings also cannot be made due to the lack of measurement conditions descriptions,

* Czech Technical University in Prague, the Faculty of Biomedical Engineering, nam. Sitna 3105, Kladno, Czech Republic; kutilek@fbmi.cvut.cz, vladimir.socha@fbmi.cvut.cz, kutilek@fbmi.cvut.cz, slavka.viteckova@fbmi.cvut.cz 


\begin{tabular}{|l|l|}
\hline $\begin{array}{l}\text { Input } \\
\text { Measurement } \\
\text { conditions and } \\
\text { Rules }\end{array}$ & $\begin{array}{l}\text { Output } \\
\text { Quality of the } \\
\text { adhesion }\end{array}$ \\
$\begin{array}{l}\text { IF cricital force is normal THEN quality } \\
\text { of the adhesion is moderate } \\
\text { IF cricital force is high THEN quality of the } \\
\text { adhesion is excellent }\end{array}$ & \\
\hline $\begin{array}{l}\text { Input values } \\
\text { Cricital force }(\mathrm{N})\end{array}$ & Output value \\
$\begin{array}{l}\text { Loading rate }(\mathrm{N} / \mathrm{min}) \\
\text { Displacement rate (mm/min) } \\
\text { Coefficient of friction }(-)\end{array}$ & $\begin{array}{l}\text { Quality of the } \\
\text { Tip radius }(\mu \mathrm{m})\end{array}$ \\
\begin{tabular}{l} 
Tip wear $(\mu \mathrm{m})$ \\
\hline
\end{tabular} & \\
\hline
\end{tabular}

Fig. 1. Basic idea behind a fuzzy system is to interpret an input, and based on sets of if-then rules, obtain an output

Table 1. Designed and recommended standard measurement conditions, [5]

\begin{tabular}{ll}
\hline Film thickness & from $0.10 \mu \mathrm{m}$ to $20 \mu \mathrm{m}$ \\
Preload & $1 \mathrm{~N}$ for $\mathrm{L}_{\max }<20 \mathrm{~N} ;$ \\
& $5 \mathrm{~N}$ for $\mathrm{L}_{\max }>20 \mathrm{~N}$ \\
& $10 \mathrm{~N} / \min$ for $\mathrm{L}_{\max }<20 \mathrm{~N} ;$ \\
& $100 \mathrm{~N} / \min$ for $\mathrm{L}_{\max }>20 \mathrm{~N}$ \\
& $10 \pm 0.1 \mathrm{~mm} / \mathrm{min}$ \\
Displacement speed PLST & Rockwell C \\
Stylus geometry & $\mathrm{Ra}<0.5 \mu \mathrm{m}$ \\
Surface roughness & $\mathrm{HV}>5 \mathrm{GPa}$ \\
Film hardness & $3 \mathrm{x}$ \\
Min. number of & 100 to $500 \mathrm{x}$ \\
test operations & 20 to $24{ }^{\circ} \mathrm{C}$ \\
Optical microscope & $50 \pm 10 \%$ \\
Temperature & \\
Relative humidity &
\end{tabular}

or due to the application of nonstandard conditions [5, 20-25]. One option in the recent situation is the use of the standards with the addition of prescribed measurement procedures and conditions. The other option is a design of a knowledge-based system based on the existing international standards and knowledge of adhesion of thin films. The knowledge-based system can convert the measurement conditions and measured data so that data can be effectively used for results comparisons. Recently, no rule based expert system based on artificial intelligence for identifying the quality of the practical adhesion strength is used. Fuzzy logic as a part of artificial intelligence has been tested only for detecting the position of the critical forces in the recorded acoustic emission signal. Never before has the fuzzy logic been applied to identify the quality of the adhesion at different measurement conditions, as well as and the artificial intelligence has never been used as an expert system for evaluating the measurement results.

\section{INTERNATIONAL STANDARDS FOR EVALUATION OF ADHESION}

For the starting point of the study, overlapping measurement conditions and procedures were discovered, based on the comparison of standardized and recommended measurement conditions [1-4]. Three international standards recommend a film thickness from $0.10 \mu \mathrm{m}$ to $0.50 \mu \mathrm{m}$, and two of them from $0.10 \mu \mathrm{m}$ to $20 \mu \mathrm{m}[5,6]$, while recommended thickness ranges range from $0.10 \mu \mathrm{m}$ to $20 \mu \mathrm{m}$. Due to lesser residual stresses in thinner films, thinner films have a tendency to produce higher critical scratch loads $[3,26,27,30]$. The roughness of the surface should normally be $\mathrm{Ra}<0.5 \mu \mathrm{m}$, and following the recommended surface roughness avoids decreases in the critical scratch loads in higher substrate roughness [3, 26]. A surface roughness value $\mathrm{Ra}$ of $0.50 \mu \mathrm{m}$ can cause oscillations of $0.1 \mathrm{~N}$ [1]. According to C1624-05, film hardness should be $\mathrm{HV}>5 \mathrm{Gpa}$ [3]. As for the stylus geometry, spherical diamond tip radius of $200 \mu \mathrm{m}$ (Rockwell C) will be used, in contrast with D7187 definition, stating the spherical tip of $100 \mu \mathrm{m}$. Since larger loading area causes lower stress applied, higher radius tips should not be used, [3], [26-28], and materials with lower coefficient of friction cause the critical scratch loads to decrease, with diamond having the lower coefficient of friction $[3,26]$.

The preload for measurement according to D7187 standard should range from 0.1 to $1 \mathrm{mN}$, and $1 \mathrm{~N}$ if $\mathrm{L}_{\max }<$ $20 \mathrm{~N}$ for measurement according to two standards $[1,3,8]$. The loading rate of the progressive loading scratch test mode is $100 \mathrm{~N} / \mathrm{min}$ for two standards [1,3] and in the D7187 the rate to $200 \mathrm{mN} / \mathrm{min}$ is recommended. The loading rate of $100 \mathrm{~N} / \mathrm{min}$ should be used because most macro and micro-scratch testers can work in this range. The loading rate of $10 \mathrm{~N} / \mathrm{min}$ could be used if $\mathrm{L}_{\max }<$ $20 \mathrm{~N}$. The loading rate of $10 \mathrm{~N} / \mathrm{min}$ if $\mathrm{L}_{\max }<20 \mathrm{~N}$ or $100 \mathrm{~N} / \mathrm{min}$ if $\mathrm{L}_{\max }>20 \mathrm{~N}$ is recommended. An increase in the load rate increases the critical scratch load $[3,26,27]$. The displacement speed of the progressive loading scratch test mode is $10 \pm 0.1 \mathrm{~mm} / \mathrm{min}$ for all standards [1-4], though the D7187 recommends the speed from 0.5 to $10 \mathrm{~mm} / \mathrm{min}$. A decrease in the displacement (sliding) speed increases the critical scratch load [3,26, 27]. The D7187 also differs in the minimum number of operations (three), while the two standards recommend five operations, however three tests will be considered sufficient. The following table sums up the recommended standard measurement conditions (Table 1).

For the sake of securing the comparability of results, it is vital to follow the standards, which recent papers on the topic have widely neglected, since they failed to specify the measurement conditions and therefore also the 
Table 2. The general "if-then" rules of critical force depending on the measurement conditions

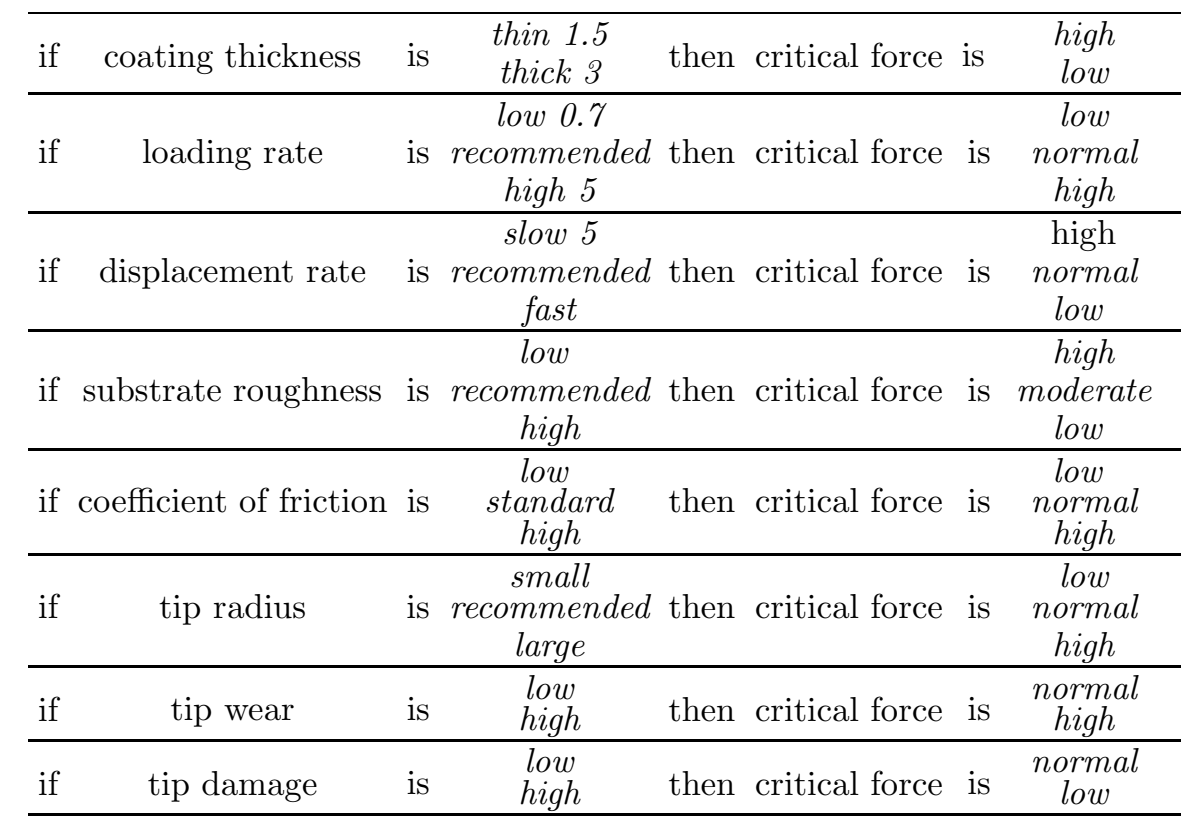

way of identification of critical load. Also, academic studies mostly mention only one way to find critical normal force $\mathrm{L}$ (the normal force at which failure occurs), in contrast with multiple ways defined by standards [8, 20-25]. In general, a series of failure modes can be observed and used to study the mechanical behavior of the coated surface, where the onset of the $n$-th failure mode defines the critical normal force $\mathrm{L}_{\mathrm{cn}}[1-4]$. However, the critical force $\mathrm{L}_{\mathrm{c} 2}$ is considered as a practical adhesion in the most scientific articles [8]. The force $\mathrm{L}_{\mathrm{c} 2}$ is associated with the onset of chipping failure or local interfacial spallation, indicating adhesive failure between the coating and the substrate. The evaluation of the described scratch test requires microscope to display the scratch and to identify the important failure mode points in the scratch. The international standards and knowledge of adhesion of thin films can be used to design a knowledge-based system. The knowledge-based system can convert the measurement conditions and measured data so that data can be used for comparison of measured results.

\section{FUZZY RULE BASED EXPERT SYSTEM FOR EVALUATION OF ADHESION}

The conditions enabling us to design expert systems are the knowledge about the behaviour of a thin film and changes of the scratch test conditions. It follows that the existing international standards and knowledge of adhesion can be used as models/patterns for setting the fuzzy expert system, which could be used to identify the quality of the practical adhesion strength. Also, artificial intelligence methods implemented in MatLab toolboxes [36] can be used in the process. The use of fuzzy logic, as a kind of "soft" computing techniques, enables us to overcome the problems encountered using "hard" computing techniques [34]. More precisely, coating adhesion studies require linguistic description, and since fuzzy logic enables us to avoid the use of numbers and symbols, the adhesion could be linguistically qualified as poor, moderate or excellent, $[5,6]$.

Empiric findings and knowledge can be translated into fuzzy if-then rules through the use of language. The fuzzy expert system uses a fuzzy if-then rule base consisting of a set of intuitive fuzzy rules, consisting of interpreting an input, and based on sets of if-then rules, inferring an output. The transition from "belonging to a set" to "notbelonging to a set" is gradual and is characterized by a membership function that gives fuzzy sets flexibility in modelling commonly used linguistic expressions, such as the "displacement rate is slow" or "loading rate is recommended". A fuzzy if-then rule assumes the form: if $\mathrm{x}$ is $\mathrm{A}$ then $\mathrm{y}$ is $\mathrm{B}$, where $\mathrm{A}$ and $\mathrm{B}$ are linguistic variables defined by fuzzy sets on universes of discourse $\mathrm{X}$ and $\mathrm{Y}$, respectively (Fig. 1). The " $\mathrm{x}$ is $\mathrm{A}$ " is the antecedent and the " $\mathrm{y}$ is $\mathrm{B}$ " is the consequence $[5,6]$.

The output in this scheme is the quality of adhesion depending on the measurement conditions, based on the fuzzy if-then rules. ISO 2409 ranks the quality of adhesion, by numbers ranging from 0 (no coating removed from the substrate surface - excellent adhesion) through very good (1), good (2), moderate (3), poor (4), to very poor (5-more than $65 \%$ of the coating removed) [35]. This can linguistically described by variables representing excellent (0), moderate (2.5), poor $(5)[5,6]$.

The output (quality of adhesion) is significantly influenced by the input variables, which are: critical force, coating thickness, loading rate, displacement rate, substrate roughness, coefficient of friction, tip radius, tip wear and tip damage, $[3,8]$. The quality of practical adhe- 
Table 3. The general "if-then" rules of adhesion defined by critical force depending on the measurement conditions, and if-then rule weights [5]

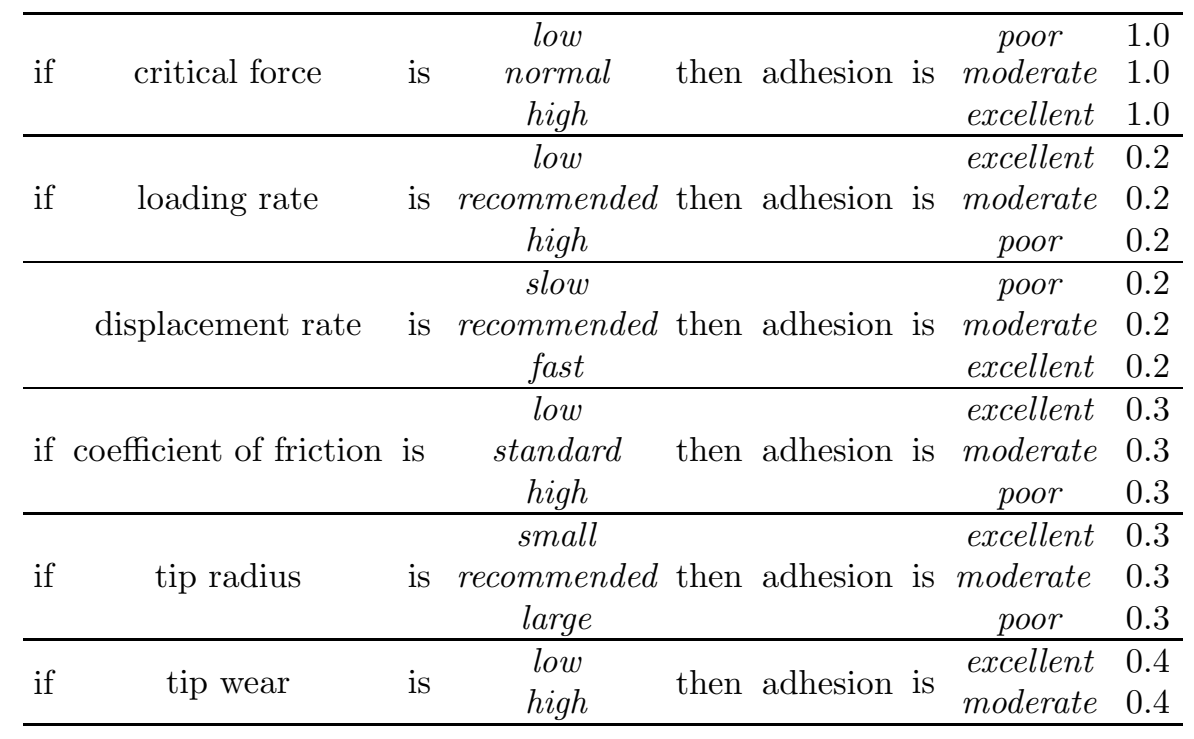

Table 4. Fuzzy sets of variables, linguistic expressions based on measurement conditions and parameters for definition of triangular ( $\mathrm{a}, \mathrm{b}$ and c) membership function [6]

\begin{tabular}{|c|c|c|c|c|c|}
\hline & Fuzzy variable & Fuzzy set & a & $\mathrm{B}$ & c \\
\hline \multirow{3}{*}{ Output } & \multirow{3}{*}{$\begin{array}{l}\text { Adhesion } \\
(-)\end{array}$} & poor & 5 & 5 & 2.5 \\
\hline & & moderate & 5 & 2.5 & 1 \\
\hline & & excellent & 2.5 & 0 & 0 \\
\hline \multirow{17}{*}{ Input } & \multirow{3}{*}{$\begin{array}{l}\text { Critical force } \\
\text { (N) }\end{array}$} & low & 0 & 0 & 30 \\
\hline & & normal & 0 & 30 & 60 \\
\hline & & high & 30 & 60 & 60 \\
\hline & \multirow{3}{*}{$\begin{array}{l}\text { Loading rate } \\
(\mathrm{N} / \mathrm{min})\end{array}$} & low & 0 & 0 & 100 \\
\hline & & recommended & 0 & 100 & 150 \\
\hline & & high & 100 & 150 & 150 \\
\hline & \multirow{3}{*}{$\begin{array}{l}\text { Displacement rate } \\
\qquad(\mathrm{mm} / \mathrm{min})\end{array}$} & slow & 0 & 0 & 10 \\
\hline & & recommended & 0 & 10 & 50 \\
\hline & & fast & 10 & 50 & 50 \\
\hline & \multirow{3}{*}{$\begin{array}{c}\text { Coefficient of friction } \\
(-)\end{array}$} & low & 0 & 0 & 0.2 \\
\hline & & standard & 0 & 0.2 & 0.5 \\
\hline & & high & 0.2 & 0.5 & 0.5 \\
\hline & \multirow{3}{*}{$\begin{array}{l}\text { Tip radius } \\
(\mu \mathrm{m})\end{array}$} & small & 0 & 0 & 200 \\
\hline & & recommended & 0 & 200 & 300 \\
\hline & & large & 200 & 200 & 300 \\
\hline & \multirow{2}{*}{$\begin{array}{l}\text { Tip wear } \\
(\mu \mathrm{m})\end{array}$} & low & 0 & 0 & 50 \\
\hline & & high & 0 & 50 & 50 \\
\hline
\end{tabular}

sion strength is also defined by the critical force, following that the higher critical force identified, the higher quality of adhesion we get, and vice versa. Table 2 demonstrates the general if-then rules applied to these variables, applied in accordance with accordance with ASTM C1624-05 [3] and analysis, [5,6]. Of course, these if-then rules cannot be applied in case of the critical force measured during non-standard measurement conditions, since a conversion would be necessary, and modifications to these rules would be needed to compare the quality of adhesion measured in standard and non-standard mea- surement conditions. Although it is known how the critical force is changed if the measurement conditions are changed, and the values can be converted into those expected from standard measurement, it would require expert knowledge to determine the new rules and their impact on the system, $[5,6]$. The rules and their weights in the Table 3 are designed in accordance with the expert knowledge and statements in the $[3,6,26-30]$. The new if-then rules of adhesion identified by measured critical force depending on the measurement conditions are mentioned in Table $3,[5,6]$.

The characteristics rules other than the measured critical force don't have as much weight as the rules for the measured critical force, which is the most important characteristic. Because of the conversion of the measured critical force to the expected critical force, most rules (Table 3) have the opposite effects on the quality of adhesion than the general rules (Table 2) describing the change in critical force. For example, if the increase of the measured critical force is caused by the increase of the loading rate (Table 2), then, in fact, the critical force is lower under standard measurement conditions, ie standard loading rate $\left(10 \mathrm{~N} / \mathrm{min}\right.$ for $\mathrm{L}_{\max }<20 \mathrm{~N}$ or $100 \mathrm{~N} / \mathrm{min}$ for $\left.L_{\max }>20 \mathrm{~N}\right)$. This means that if the loading rate is higher than the standard loading rate, the quality of adhesion is lower under standard measurement conditions than the identified quality of adhesion. Only the critical force has a direct impact on the quality of adhesion, Table 3. Since coating thickness and substrate roughness are features of the specimen and are not features of measurement conditions, they are not considered in the new rules.

The fuzzy sets and membership functions need to be defined in the next step, since the input/output is a numerical value limited to the universe of discourse of the input/output variable. Each variable is a fuzzy variable and each variable is described by fuzzy sets $[34,36]$. We 


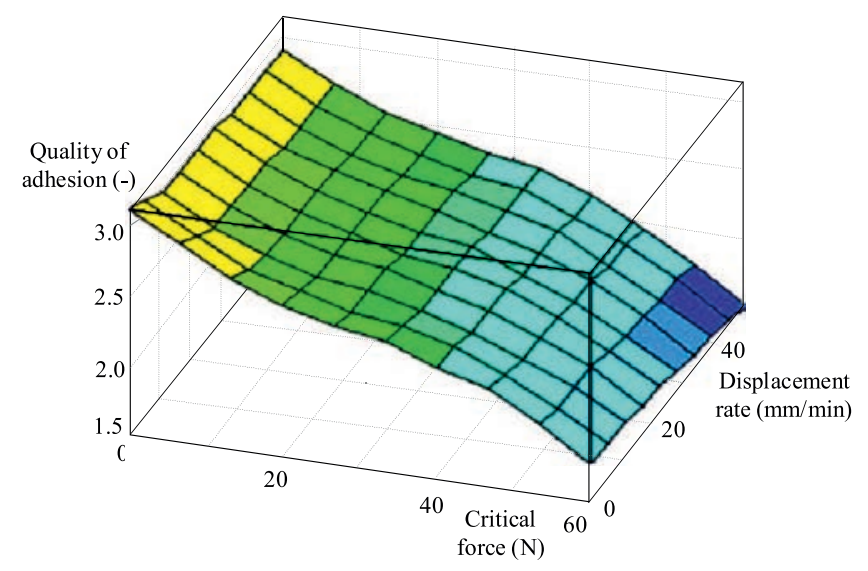

Fig. 2. 3-D plot of a two-input and one-output of fuzzy expert system

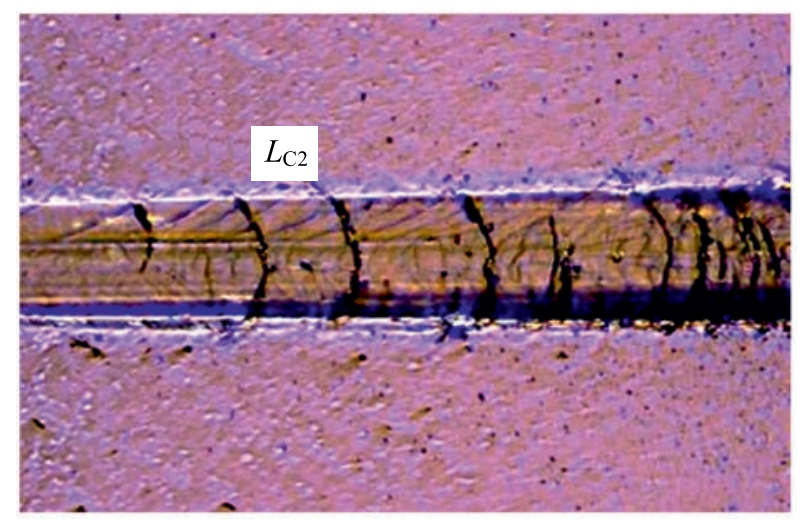

Fig. 3. Conformal-type buckling cracks with local interfacial spallation (sample-film thickness $470 \mathrm{~nm}$, Tab. 5)

Table 5. Measurement conditions of different samples with the evaluated critical force and quality of adhesion

\begin{tabular}{|c|c|c|c|c|}
\hline \multicolumn{4}{|c|}{ Input } & Output \\
\hline $\begin{array}{l}\text { Film } \\
\text { thickness } \\
(\mathrm{nm}) \\
\end{array}$ & $\begin{array}{c}\text { Loading } \\
\text { rate } \\
(\mathrm{N} / \mathrm{min}) \\
\end{array}$ & $\begin{array}{c}\text { Displacement } \\
\text { speed } \\
(\mathrm{mm} / \mathrm{min}) \\
\end{array}$ & $\begin{array}{l}\text { Critical } \\
\text { force } \\
(\mathrm{N})\end{array}$ & $\begin{array}{l}\text { Quality of } \\
\text { adhesion } \\
(-) \\
\end{array}$ \\
\hline 80 & 14 & 5 & 6.0 & 2.85 \\
\hline 100 & 10 & 1.7 & 2.6 & 3.00 \\
\hline 330 & 100 & 10 & 5.9 & 2.80 \\
\hline 360 & 100 & 10 & 10.8 & 2.70 \\
\hline 470 & 100 & 10 & 8.8 & 2.75 \\
\hline
\end{tabular}

defined the membership functions to which the inputs belong in each of the appropriate fuzzy antecedent sets (see Table 4). The output variable is represented by consequent fuzzy sets. The membership functions to which the outputs belong in each of the appropriate fuzzy consequent sets were defined (see Table 4) $[5,6]$.

The premise of the proposal of described fuzzy expert system is what the method of identification of the quality of adhesion is based on. The fuzzy expert system has six input variables which it interprets, and based on sets of ifthen rules, infers an output variable, see Fig. 1. The Fuzzy
Toolbox and Mamdani Fuzzy Inference System (FIS) in MatLab are used to create the described fuzzy expert system, which uses processes such as PROD (product) for implication, SUM (simply the sum of each rule's output set) and BISECTOR for defuzzification, however the using is very user-friendly, and the methods of the processes can be modified.

The fuzzy expert system's typical mapping of a twoinput one-output can be depicted in a $3-\mathrm{D}$ plot. The quality of adhesion is identified by two inputs (critical force and displacement rate) in the plot, Fig. 2, representing the input-output dependence based on two relationships.

\section{APPLICATION OF FUZZY EVALUATION AND RESULTS}

The testing and verification of fuzzy rule based expert system used information on the variables of measurement conditions and measured characteristics of diamond like carbon (DLC) films. The thickness of the films ranged from 80 to $470 \mathrm{~nm}$. Titanium alloy Ti6Al4V was used as a substrate. The critical force of thin films prepared by PLD technique was measured by the REVETEST system (CSM Instruments Inc.). The progressive loading scratch test mode was used, while film thickness; loading rate; displacement speed; were the variable measurement conditions for film testing Table 5 . Pre-load, $5 \mathrm{~N}$; surface roughness, $0.25 \mu \mathrm{m}$; tip radius, $200 \mu \mathrm{m}$ (Rockwell $\mathrm{C}$ the tip wear was not detected), and coefficient of friction of 0.2 between the diamond and the test surfaces were constant measurement conditions for film testing. The temperature of $20^{\circ} \mathrm{C}$ and $55 \%$ relative humidity were the outer conditions during the tests.

Five samples were used under the different conditions for scratches that were made on them. Graphic information was provided by REVETEST (magnification higher than 100:1) about the shape of a scratch and failure mode points were visually confirmed by the photographs of the scratch. There were three types of failure mode points identified (critical normal forces in each scratch under optical microscope), [8]. Evaluation of DLC layer by microscopic examination and identification of the second critical force $\mathrm{L}_{\mathrm{c} 2}$, were made as well, Fig. 3 .

The average second critical force $\left(i e \mathrm{~L}_{\mathrm{c} 2}\right)$ was calculated for each specimen, while each specimen was measured three times $[5,6]$. The input variables are: critical force, (the layers differed in the identified critical forces) loading rate, displacement rate, coefficient of friction, tip radius, tip wear, Table 4 . Fuzzy expert system interprets the input $\left(\mathrm{L}_{\mathrm{c} 2}\right.$, and information about the measurement conditions) and based on sets of if-then rules, infers the output - quality of adhesion. Thinner films were shown to have better quality of adhesion $[3,26,27,30]$. 


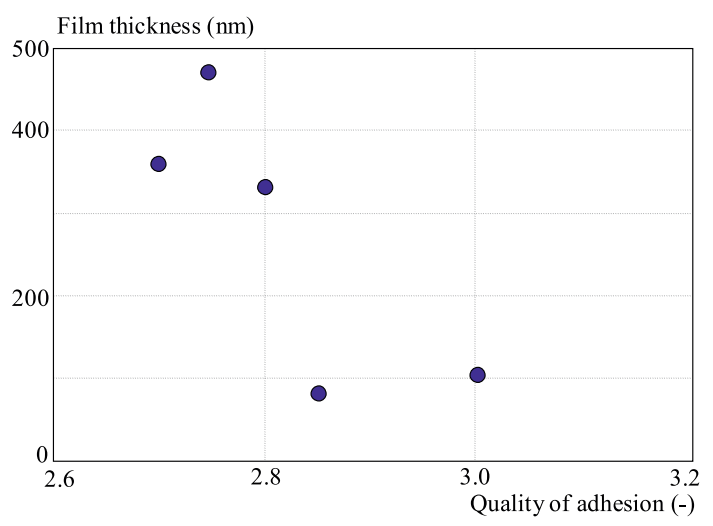

Fig. 4. The dependence of the identified quality of adhesion of the film thickness

\section{DISCUSSION}

In this demonstration of the application of designed fuzzy expert system, it was found that estimated quality of adhesion of our layers is rather close to the 3 which corresponds to rather low-quality of adhesion of used films, which is not the case of thinner films, which proved better quality of adhesion, which reinforces the general assumption. The results must, however, be seen as approximate and illustrative, since the system setting strongly influences the quality of adhesion. The system is set by the rules (Table 3) and membership functions for fuzzy sets (Table 4). The estimation of the quality of adhesion proves more accurate in case of modifying a small number of input variables from the standard measurement conditions, due to the error accumulation in the estimation by the designed fuzzy expert system, which estimates the quality of adhesion less accurately if all input variables are not standard measurement conditions.

\section{CONCLUSIONS}

The fuzzy expert system was designed using recommended standardized conditions and procedures for measuring the practical adhesion of a film whose thickness ranges from $0.10 \mu \mathrm{m}$ to $20 \mu \mathrm{m}$, which is typical of biocompatible nano- and micro-thin films. Designed expert system for rough comparison of the practical adhesion of thin layers can be used if the recommended conditions are not met.

MatLab was used for creating the tested Fuzzy rule based expert system, using a knowledge base of expertise. The fuzzy system offers a rough comparison of the properties of thin layers if standard measurement conditions are not used, allowing for a rough but relevant comparisons of results obtained in different settings and different facilities.

One and only tip shape was used for the study spherical diamond tip radius of $200 \mu \mathrm{m}$ (Rockwell C), and we do not recommend the use of any other kind of tip, since it influences the behavior of the layer as well as adhesion to the substrate, plus there are no nano- and micro-scratch test international standards for other types of tips.

Since the proposed methods attempt to establish a uniform measurement conditions, the recommended measurement conditions of the progressive loading scratch test mode have to be followed, otherwise the obtained values of the quality of adhesion may and will be incomparable with other academic results.

The comparison of the results of evaluation of the recommended measuring conditions and non-standard measurement conditions will be subjects of the future testing, which is to adjust the expert system to different kinds of measurement conditions. The desired outcome is the finding of more accurate system parameters for the evaluation of specific types of thin film materials.

\section{Acknowledgment}

This work was done at the Joint Department of Biomedical Engineering CTU and Charles University in Prague in the framework of research program No.VG201 02015002 (2010-2015, MV0/VG), sponsored by the Ministry of the Interior of the Czech Republic, and research program No.SGS13/091/OHK4/1T/17 (2013, CTU).

\section{REFERENCES}

[1] EN 1071-3, Advanced Technical Ceramics - Method of Test for Ceramic Coatings - Part 3: Determination of Adhesion and other Mechanical Failure Modes by a Scratch Test. Brussels: International Organization for Standardization, (2006).

[2] International Standard ISO 20502: Fine Ceramics (Advanced Ceramics, Advanced Technical Ceramics) - Determination of Adhesion of Ceramic Coatings by Scratch Testing. Geneva: International Organization for Standardization, (2005).

[3] Standard C1624 (C1624-05): Test Method for Adhesion Strength and Mechanical Failure Modes of Ceramic Coatings by Quantitative Single Point Scratch Testing. Conshohocken: ASTM International, (2005).

[4] Standard ASTM D7187: Test Method for Measuring Mechanistic Aspects of Scratch/Mar Behavior of Paint Coatings by a Nanoscratching. Conshohocken: ASTM International, (2005).

[5] KUTILEK, P.-MIKSOVSKY, J.-VITECKOVA, S.-DOBESOVA, E.: The Evaluation and Comparison of the Practical Adhesion Strength of Biocompatible Nano and Micro Thin Films by Fuzzy Logic.

[6] KUTILEK, P.-MIKSOVSKY, J.: The Procedure of Evaluating the Practical Adhesion Strength of New Biocompatible Nano-and Micro-Thin Films in Accordance with International Standards, Acta of Bioengineering and Biomechanics 13 No. 3 (2011), 87-94.

[7] BULL, J.: Failure Modes in Scratch Adhesion Testing, Surf. Coat. Technol. 50 (1991), 25-32.

[8] PERRY, A.: The Adhesion of Chemically Vapour-Deposited Hard Coatings to Steel - the Scratch Test, Thin Solid Films 78 (1981), 77-93.

[9] PERRY, A. : Scratch Adhesion Testing of Hard Coatings, Thin Solid Films 107 (1983), 167-180.

10] STEINMANN, P.-HINTERMANN, H. : Adhesion of TiC and Ti(C,N) Coatings on Steel, J. Vac. Sci. Technol. 3 No. 6 (1985), 2394-2400. 
[11] VALLI, J.: TiN Coating Adhesion Studies Using the Scratch Test Method, J. Vac. Sci. Technol. 3 No. 6 (1985), 2411-2414.

[12] VALLI, J. : A Review of Adhesion Test Methods for Thin Hard Coatings, J. Vac. Sci. Technol. 4 No. 6 (1986), 3007-3014.

[13] VALLI, J.-MAKELA, U.-MATTHEWS, A. : Assessment of Coating Adhesion, Surf. Eng. 2 No. 1 (1986), 49-53.

[14] PERRY, A.: Scratch Adhesion Testing: a Critique, Surf. Eng. 2 No. 3 (1986), 183-190.

[15] BULL, S.-RICKERBY, D.-MATTHEWS, A.-LEYLAND, A.-PACE, A.-VALLI, J.: The Use of Scratch Adhesion Testing for the Determination of Interfacial Adhesion: the Importance of Frictional Drag, Surf. Coat. Technol. 36 (1986), 503-517.

[16] STEBUT, J.-REZAKHANLOU, R.-ANOUN, K.-MICHEL, H.-GANTOIS, M.: Major Damage Mechanisms During Scratch and Wear Testing of Hard Coatings on Hard Substrates, Thin Solid Films 181 (1986), 555-564.

[17] BROMARK, M.-LARSSON, M.-HEDENQVIST, P.-OLSSON, M.-HOGMARK, S.: Influence of Substrate Surface Topography on the Critical Normal Force in Scratch Adhesion Testing of TiN-Coated Steels, Surf. Coat. Technol. 52 No. 195-203 (1992).

[18] HOLMBERG, K.: Surface Fracture Toughness Measurement by the Scratch Test Methodjour Tribologia-Finn. J. Tribol..

[19] HEDENQUist, P.-OLSSON, M.-JACOBSON, S.-HOGMARK, S.: Failure Mode Analysis of TiN-Coated High Speed Steel: in situ Scratch Test Adhesion Test in Scanning Electron Microscope, Surf. Coat. Technol. 41 (1990), 31-49.

[20] NAKAO, S.-KIM, J.-CHOI, J.-MIYAGAWA, S.-MIYAGAWA, Y.: Micro-Scratch Test of DLC Films on Si Substrates Prepared by Bipolar Type Plasma Based Ion Implantation, Surface \& Coatings Technology 201 (2007), 8334-8338.

[21] FUNADA, Y.-AWAZU, K.-YASUI, H.-SUGITA, T. : Adhesion Strength of DLC Films on Glass with Mixing Layer Prepared by IBAD, Surface \& Coatings Technology 128-129 (2000), 308-312.

[22] HORIUCHI, T.-YOSHIDA, K.-KANO, M.-KUMAGAI, M.-SUZUKI, T.: Evaluation of Adhesion and Wear Resistance of DLC Films Deposited by Various Methods, Plasma Processes and Polymers 6 (2009), 410-416.

[23] Durability Evaluation of Ultra-Thin Diamond-Like Carbon Films: Application Note. Center for Tribology, Inc. (Online) http://www.cetr.com/Brochures/scratch_resistance.pdf June 2011.

[24] ZHANG, T.-HUAN, Y.: Nanoindentation and Nanoscratch Behaviors of DLC Coatings on Different Steel Substrates, Composites Science and Technology 65 (2005), 1409-1413.

[25] VERCAMMENA, K.-Van ACKERA, A.-VANHULSELA, A.-BARRIGAB, J.-ARNSEKC, A.: Tribological Behaviour of DLC Coatings in Combination with Biodegradable Lubricants, Tribology International 37 (2004), 983-989.

[26] BLAU, J.: Lab Handbook of Scratch Testing. Chapter $7-$ Scratch Adhesion Testing, Oak Ridge: Blue Rock Technical Publications, 2002.

[27] RANDALL, X.-FAVARO, G.-FRANKEL, C. : Effect of Intrinsic Parameters on the Critical Load as Measured with the Scratch Test Method, Surface and Coatings Technology 137 (2001), 146-151.
[28] XIE, Y.-HAWTHORNE, M.: Effect of Contact Geometry on the Failure Modes of Thin Coatings in the Scratch Adhesion Test, Surface and Coatings Technology 155 (2002), 121-129.

[29] ICHIMURA, H.-ISHII, Y.: Effects of Indenter Radius on the Critical Load in Scratch Testing, Surface and Coatings Technology 165 (2003), 1-7.

[30] MITTAL, K. L.: Scratch Adhesion Testing of Coated Surfaces - Challenges and New Directions, Vol. 2 - Adhesion Measurement of Films and Coatings, Zeist: VSP International Science Publishers, 2001.

31] KANDEL, A. : Fuzzy Expert Systems, Boca Raton: CRC Press, 1991.

[32] SILER, W.-BUCKLEY, J. : Fuzzy Expert Systems and Fuzzy Reasoning, J. Wiley \& Sons, New York, 2005.

[33] ZHU, Q.-QIN, D.-YUAN, F.-CHEN, J.: Evaluation of Interfacial Adhesion Property for Thin Hard Films with Fuzzy Method, Journal of Wuhan University of Technology 25 No. 5 (2010), 829-831.

[34] ZADEH, L. : Fuzzy sets, Information Control 8 (1965), 338-353.

[35] SHOJAEI, A.-FATHI, R.-SHEIKH, N. : Adhesion Modification of Polyethylenes for Metallization using Radiation-Induced Grafting of Vinyl Monomers, Surface and Coatings Technology 201 No. 16-17 (2007), 7519-7529.

36] SIVANANDAM, S., SUMATHI, S., DEEPA, S.: Introduction to Fuzzy Logic Using MATLAB, Springer, Berlin, 2010.

Received 15 April 2013

Patrik Kutílek, born in Pardubice (Czech Republic) in 1975, received his MSc degree in aircraft and rocket technology and $\mathrm{PhD}$ degree in cybernetics and military robotics from the Faculty of Military Technology, University of Defence in Brno, in 2005. He also received MSc degree in management studies from the Nottingham Trent University. He worked for several years for Ministry of Defence of the Czech Republic as a cryptographic engineer, and worked on a number of research projects, is the authorized person of 8 utility models and authored more than 40 journal, book chapter and conference papers. He works at Faculty of Biomedical Engineering of the Czech Technical University in Prague as a lecturer from 2007. His research interests include artificial intelligence and signal processing.

Slávka Vitečková received the master degree with emphasis in Information Technologies from the Palacky University in Olomouc, Czech Republic, in 2010. Currently, she is PhD student and research engineer at Czech Technical University in Prague, Faculty of Biomedical Engineering. Her research interests include artificial intelligence.

Vladimír Socha, born in Piešt’any (Slovakia) in 1989, completed his first level of university studies in air transport management and also in prosthetics and orthotics at Technical University of Koice. He received the masters degree in Biomedical and Clinical Techniques at Czech Technical University in Prague, Faculty of Biomedical Engineering. Currently, he is $\mathrm{PhD}$ student, assistant and research engineer at Czech Technical University in Prague, Faculty of Biomedical Engineering. His research interests include artificial intelligence and signal processing. 